\title{
Multi-compound Polarization by DNP Allows Simultaneous Assessment of Multiple Enzymatic Activities In Vivo
}

\author{
David M. Wilson ${ }^{1}$, Kayvan R. Keshari ${ }^{1,3}$, Peder E. Z. Larson ${ }^{1}$, Albert P. Chen ${ }^{2}$, Simon Hu ${ }^{1}$, \\ Mark Van Criekinge ${ }^{1}$, Robert Bok ${ }^{1}$, Sarah J. Nelson ${ }^{1}$, Jeffrey M. Macdonald ${ }^{3}$, Daniel B. \\ Vigneron $^{1}$, and John Kurhanewicz ${ }^{1}$ \\ ${ }^{1}$ Department of Radiology, University of California San Francisco (UCSF), San Francisco, \\ California, United Sates \\ ${ }^{2}$ GE Healthcare, Menlo Park, CA 94025 \\ ${ }^{3}$ Department of Biomedical Engineering, University of North Carolina Chapel Hill (UNC-CH), Chapel \\ Hill, North Carolina, United States
}

\begin{abstract}
Methods for the simultaneous polarization of multiple ${ }^{13} \mathrm{C}$-enriched metabolites were developed to probe several enzymatic pathways and other physiologic properties in vivo, using a single intravenous bolus. A new method for polarization of ${ }^{13} \mathrm{C}$ sodium bicarbonate suitable for use in patients was developed, and the co-polarization of ${ }^{13} \mathrm{C}$ sodium bicarbonate and $\left[1-{ }^{13} \mathrm{C}\right]$ pyruvate in the same sample was achieved, resulting in high solution state polarizations (15.7\% and $17.6 \%$, respectively) and long spin-lattice relaxation times $\left(\mathrm{T}_{1}\right)(46.7 \mathrm{~s}$ and $47.7 \mathrm{~s}$ respectively at $3 \mathrm{~T})$. Consistent with chemical shift anisotropy dominating the $\mathrm{T}_{1}$ relaxation of carbonyls, $\mathrm{T}_{1}$ values for ${ }^{13} \mathrm{C}$ bicarbonate and $\left[1-{ }^{13} \mathrm{C}\right]$ pyruvate were even longer at $3 \mathrm{~T}\left(49.7 \mathrm{~s}\right.$ and $67.3 \mathrm{~s}$, respectively). Co-polarized ${ }^{13} \mathrm{C}$ bicarbonate and $\left[1-{ }^{13} \mathrm{C}\right]$ pyruvate were injected into normal mice and a murine prostate tumor model at 3T. Rapid equilibration of injected hyperpolarized ${ }^{13} \mathrm{C}$ sodium bicarbonate with ${ }^{13} \mathrm{C} \mathrm{CO}_{2}$ allowed calculation of $\mathrm{pH}$ on a voxel by voxel basis, and simultaneous assessment of pyruvate metabolism with cellular uptake and conversion of $\left[1-{ }^{13} \mathrm{C}\right]$ pyruvate to its metabolic products. Initial studies in a Transgenic Adenocarcinoma of Mouse Prostate (TRAMP) model demonstrated higher levels of hyperpolarized lactate and lower $\mathrm{pH}$ within tumor, relative to surrounding benign tissues and to the abdominal viscera of normal controls. There was no significant difference observed in the tumor lactate/pyruvate ratio obtained after the injection of co-polarized ${ }^{13} \mathrm{C}$ bicarbonate and $\left[1-{ }^{13} \mathrm{C}\right]$ pyruvate or polarized $\left[1-{ }^{13} \mathrm{C}\right]$ pyruvate alone. The technique was extended to polarize four ${ }^{13} \mathrm{C}$ labelled substrates potentially providing information on $\mathrm{pH}$, metabolism, necrosis and perfusion, namely $\left[1-{ }^{13} \mathrm{C}\right]$ pyruvic acid, ${ }^{13} \mathrm{C}$ sodium bicarbonate, $\left[1,4-{ }^{13} \mathrm{C}\right]$ fumaric acid, and ${ }^{13} \mathrm{C}$ urea with high levels of solution polarization (17.5, 10.3, 15.6 and $11.6 \%$, respectively) and spin-lattice relaxation values similar to those recorded for the individual metabolites. These studies demonstrated the feasibility of simultaneously measuring in vivo $\mathrm{pH}$ and tumor metabolism using nontoxic, endogenous species, and the potential to extend the multi-polarization approach to include up to four
\end{abstract}

(C) 2010 Elsevier Inc. All rights reserved.

*Correspondence address: John Kurhanewicz, Ph.D., Professor of Radiology, Urology and Pharmaceutical Chemistry, Byers Hall, Room 203E, 1700 4th Street, San Francisco, CA 94158-2330, Tel: (415) 514-9711, Fax: (415) 514-4714,

John.Kurhanewicz@ radiology.ucsf.edu.

Publisher's Disclaimer: This is a PDF file of an unedited manuscript that has been accepted for publication. As a service to our customers we are providing this early version of the manuscript. The manuscript will undergo copyediting, typesetting, and review of the resulting proof before it is published in its final citable form. Please note that during the production process errors may be discovered which could affect the content, and all legal disclaimers that apply to the journal pertain. 
hyperpolarized probes providing multiple metabolic and physiologic measures in a single MR acquisition.

\section{Keywords}

Hyperpolarized ${ }^{13} \mathrm{C} ;\left[1-{ }^{13} \mathrm{C}\right]$ pyruvic acid; ${ }^{13} \mathrm{C}$-sodium bicarbonate; $\left[1,4-{ }^{13} \mathrm{C}\right]$ fumaric acid; ${ }^{13} \mathrm{C}$-urea; $\mathrm{pH}$

\section{Introduction}

A significant advantage of hyperpolarized MR metabolic imaging using dynamic nuclear polarization (DNP) is the ability to probe metabolic fluxes in real time, at high signal to noise (1). In vivo hyperpolarized MR is unprecedented in its ability to characterize specific enzymatic pathways $(2,3)$. Most studies to date have focused on the last step of glycolysis in which $\left[1-{ }^{13} \mathrm{C}\right]$ pyruvate is enzymatically converted to a number of products, including $\left[1-{ }^{13} \mathrm{C}\right]$ lactate mediated by the activity of lactate dehydrogenase $(\mathrm{LDH})(3-7)$. This pathway is associated with the Warburg effect, which postulates increased metabolism to lactate in tumour cells relative to normal tissue (8). More recently, a number of additional pathways have been probed, for example the conversion of bicarbonate to $\mathrm{CO}_{2}$ as mediated by carbonic anhydrase, and the conversion of glutamine to glutamate catalyzed by glutaminase $(9,10)$. Investigation of these processes by DNP-NMR has allowed mapping of $\mathrm{pH}$ in vivo and assessment of glutaminase activity in hepatic tumour cells. Additional agents showing promise in animals or perfused heart models include $\left[2-{ }^{13} \mathrm{C}\right]$ pyruvate, $\left[2-{ }^{13} \mathrm{C}\right]$ fructose, and $\left[1-{ }^{13} \mathrm{C}\right]$ lactate itself $(11-13)$. As the number of useful DNP agents continues to expand, the ability to probe multiple pathways and mechanisms simultaneously may provide valuable metabolic "signatures" associated with specific types of tumour and other diseased tissue. 1H MRS is well established as a means to establish metabolic profiles in diseased tissue in vivo $(14,15)$, but hyperpolarized MR has the additional capacity to provide kinetic information. A particular conversion pattern observed in diseased tissue may aid in targeting regions of pathology for biopsy or focal therapy, and/or better characterize the extent or aggressiveness of disease present prior to or after treatment. ${ }^{13} \mathrm{C}$ sodium bicarbonate has special promise due to its lack of toxicity and ability to probe physiological $\mathrm{pH}(9)$. A broad number of pathologic processes demonstrate alterations in $\mathrm{pH}$, including neoplastic, ischemic, and inflammatory conditions(16-19).

The dynamic nuclear polarization process requires the ${ }^{13} \mathrm{C}$ labelled probe compound to be in an amorphous (glassy) solid state with the appropriate free radical concentration at low temperatures $\left(\sim 1.2^{\circ} \mathrm{K}\right)(1)$. To accomplish an optimal preparation of a new probe or combinations of probes, the concentration of the desired agent(s), solvent/glassing agent(s), presence, concentration and type of a gadolinium agent, and the concentration and type of free radical must all be optimized. In addition, appropriate dissolution media must be prepared for each agent in order to ensure physiological $\mathrm{pH}$, osmolarity, and to preserve the longest possible $\mathrm{T}_{1}$. In this manuscript, a method for polarization of ${ }^{13} \mathrm{C}$ sodium bicarbonate is reported, without requiring the removal of cesium as in the prior published method. This method has been combined with a co-polarization technique that allows simultaneous polarization of ${ }^{13} \mathrm{C}$ bicarbonate and $\left[1-{ }^{13} \mathrm{C}\right]$ pyruvate, to perform both $\mathrm{pH}$ and metabolic mapping in vivo using a single intravenous bolus. The technique was subsequently extended to polarize four ${ }^{13} \mathrm{C}$ labelled substrates, namely $\left[1-{ }^{13} \mathrm{C}\right]$ pyruvic acid, ${ }^{13} \mathrm{C}$ sodium bicarbonate, $\left[1,4-{ }^{13} \mathrm{C}\right]$ fumaric acid, and ${ }^{13} \mathrm{C}$ urea in vitro demonstrating the potential of obtaining information on $\mathrm{pH}$, metabolism, necrosis and perfusion, in a single in vivo imaging experiment. 


\section{Materials and Methods}

\section{Sample preparation}

In all cases the ${ }^{13} \mathrm{C}$ compounds were purchased from Isotec (Miamisburg, $\mathrm{OH}$ ) and used without further purification. All natural abundance chemicals and solvents were obtained from Aldrich (Miamisburg, $\mathrm{OH}$ ). ${ }^{13} \mathrm{C}$ sodium bicarbonate: $135 \mathrm{mg}$ of ${ }^{13} \mathrm{C}$-sodium bicarbonate were dissolved in $1099 \mathrm{mg}$ of glycerol, in a sealed flask while heating with a heat-gun. The hot solution was then passed through a $0.45 \mu \mathrm{M}$ Millipore MCE Membrane filter (Fisher Scientific), and OX63 radical (Oxford Instruments, Abingdon, UK) was then dissolved to a final concentration of $20 \mathrm{mM} .{ }^{13} \mathrm{C}$ pyruvic acid: To a neat sample of $\left[1-{ }^{13} \mathrm{C}\right]$ pyruvic acid was added OX63 radical to a final concentration of $15 \mathrm{mM} .{ }^{13} \mathrm{C}$ fumaric acid: 350 milligrams of $\left[1,4-{ }^{13} \mathrm{C}\right]$ fumaric acid were mixed with 500 microliters of dimethyl sulfoxide and OX63 was added to a final concentration of $15 \mathrm{mM} .{ }^{13} \mathrm{C}$ urea: 390 milligrams of ${ }^{13} \mathrm{C}$-urea were dissolved in 895 milligrams of glycerol (Aldrich), and OX63 was added to a final concentration of 15 $\mathrm{mM}$.

\section{Co-polarization of ${ }^{13} \mathrm{C}$-Sodium Bicarbonate with $\left(1-{ }^{13} \mathrm{C}\right)$ Pyruvic Acid}

For studies at $11.7 \mathrm{~T}, 125 \mathrm{mg}$ of the ${ }^{13} \mathrm{C}$ sodium bicarbonate preparation were placed in a sample cup and frozen in liquid nitrogen, followed by addition of 2.2 microliters of pyruvic acid preparation. The sample was rapidly frozen to avoid mixing of the materials, and polarized at 94.074 GHz and 1.2-1.4K for 3.5h using a Hypersense DNP polarizer (Oxford Instruments, Abingdon, UK). This microwave frequency corresponded to the optimum microwave frequency for the ${ }^{13} \mathrm{C}$ sodium bicarbonate sample, which was approximately $10 \mathrm{MHz}$ lower than the optimum frequency observed for $\left[1-{ }^{13} \mathrm{C}\right]$ pyruvic acid. The solid state polarization build-up curve was fit to the equation: $\mathrm{P}(\mathrm{t})=\mathrm{P}_{\mathrm{eq}}\left(1-\exp ^{(-\mathrm{t} / \mathrm{Tbuildup})}\right)+$ baseline, where $\mathrm{P}_{\mathrm{eq}}$ is the equilibrium polarization achieved for the sample and $\mathrm{T}_{\text {buildup }}$ is the polarization build-up time constant. The resulting time constant was on the order of $3500 \mathrm{~s}$, similar to that observed for the ${ }^{13} \mathrm{C}$ bicarbonate preparation alone. The sample was subsequently dissolved in $6.3 \mathrm{~mL}$ of water containing $0.3 \mathrm{mM}$ EDTA. The solution was mixed manually in a teardrop flask, and injected using a $5 \mathrm{cc}$ syringe into a previously shimmed $10 \mathrm{~mm}$ NMR tube at $37^{\circ} \mathrm{C}$. This process required approximately 15 seconds. Percentage polarizations were quantified in solution by measuring the signal enhancement obtained by DNP polarization compared to the signal at thermal equilibrium. For studies at 3T, an identical polarization procedure was used except $250 \mathrm{mg}$ of the sodium bicarbonate solution were used, combined with 4.5 microliters of pyruvic acid and dissolved using $6.3 \mathrm{~mL}$ of water/ EDTA.

\section{Multi-compound polarization of ${ }^{13} \mathrm{C}$ sodium bicarbonate, pyruvic acid, urea and fumaric acid}

For studies at $11.7 \mathrm{~T}$, the following sample preparations (described above) were placed in a sample cup and frozen in liquid nitrogen: $30.0 \mu \mathrm{L}$ sodium bicarbonate, $1.0 \mu \mathrm{L}$ pyruvic acid, $6.0 \mu \mathrm{L}$ urea $3.0 \mu \mathrm{L}$ fumaric acid. The compounds were polarized at $94.080 \mathrm{GHz}$ and $1.2-1.4 \mathrm{~K}$ for 2 hours and subsequently dissolved in $5.0 \mathrm{~mL}$ of $100 \mathrm{mM}$ phosphate buffer $(\mathrm{pH}=7.8)$. Following dissolution, the sample was treated as above. In a separate set of experiments, identical quantities of these ${ }^{13} \mathrm{C}$ compounds were individually polarized by the usual method and dissolved using the same buffer. For murine studies at 3T, an identical polarization procedure was used except $175 \mathrm{mg}$ of the sodium bicarbonate solution were used, combined with 3 microliters of pyruvic acid, 8 microliters of fumaric acid and 20 microliters of urea. Additionally, 8 microliters of $10 \mathrm{M} \mathrm{NaOH}$ solution was frozen on top of the mixture. The sample was polarized as above and dissolved using $6.3 \mathrm{~mL}$ of water/ EDTA. 


\section{Hyperpolarized ${ }^{13} \mathrm{C}$ Spectroscopic Studies}

All 11.7T NMR studies were performed on a 11.7T Varian INOVA spectrometer $\left(125 \mathrm{MHz}{ }^{13} \mathrm{C}\right.$, Varian Instruments) using a $10 \mathrm{~mm}{ }^{15} \mathrm{~N} /{ }^{31} \mathrm{P} /{ }^{13} \mathrm{C}$ triple-tuned direct detect probe. For the acquisition of hyperpolarized ${ }^{13} \mathrm{C}$ spectra of bicarbonate and pyruvate eighty protondecoupled (WALTZ-16, $9000 \mathrm{~Hz}$ bandwidth, decoupling during acquisition only) pulse and acquire hyperpolarized ${ }^{13} \mathrm{C}$ NMR spectra (1 average, spectral window $=4000 \mathrm{~Hz}$, number of points $=16000, \mathrm{TR}=3.0 \mathrm{~s}$, acq time $=500 \mathrm{~ms}$, total acq time $=300 \mathrm{~s}$ ) were acquired every $3 \mathrm{sec}$ using a $5^{\circ}$ pulse. Spin-lattice $\left(\mathrm{T}_{1}\right)$ relaxation times were determined by performing a monoexponential fit to the signal decay curve of the hyperpolarized compounds. In all cases the $\mathrm{r}^{2}$ value for the fit was $>0.999$ where $r=$ the Pearson product moment correlation coefficient. All spectral measurements were collected at $\approx 37^{\circ} \mathrm{C}$. Signal enhancements due to hyperpolarization were calculated by integrating bicarbonate and pyruvate peaks in the first spectrum of the hyperpolarized dynamic experiment, and comparing these to the corresponding peaks in the thermal spectrum, accounting for differences in tip angle and the number of transients obtained.

\section{T $\mathrm{T}_{1}$ measurements}

All studies were performed using a 3T GE Signa ${ }^{\mathrm{TM}}$ scanner (GE Healthcare, Waukesha, WI) equipped with the MNS (multinuclear spectroscopy) hardware package. The RF coil used was a dual-tuned ${ }^{1} \mathrm{H}_{-}{ }^{13} \mathrm{C}$ coil used in prior hyperpolarized ${ }^{13} \mathrm{C}$ pyruvate mouse imaging studies $(4,6)$. For the $T_{1}$ measurement experiments, a half-echo FID sequence was used $\left(5^{\circ}\right.$ nonselective RF excitation, spectral window of $5 \mathrm{kHz}$ with 2048 points, $\mathrm{TR}=3.0 \mathrm{~s}, 64$ acquisitions, total acquisition time $=194 \mathrm{~s}$ ). Magnitude spectra were used for data processing, and magnitude decay curves were obtained for pyruvate, pyruvate-hydrate, bicarbonate and $\mathrm{CO}_{2}$, from which the $\mathrm{T}_{1}$ 's were fit to a mono-exponential decay function.

\section{Murine studies}

Five mice were imaged: a B6SJL male wild-type mouse (normal), and 4 Transgenic Adenocarcinoma of Mouse Prostate (TRAMP) mice. The coil setup was the same as described above for the $\mathrm{T}_{1}$ measurements. $\mathrm{T}_{2}$-weighted ${ }^{1} \mathrm{H}$ images were acquired in three planes using a fast spin-echo (FSE) sequence for anatomical reference. ${ }^{13} \mathrm{C}$ spectroscopic imaging was acquired immediately upon completion of a $15 \mathrm{~s}, 350 \mu \mathrm{L}$ injection of the dissolved copolarized ${ }^{13} \mathrm{C}$ bicarbonate and $\left[1-{ }^{13} \mathrm{C}\right]$ pyruvate $\left(55 \mathrm{mM}{ }^{13} \mathrm{C}\right.$ bicarbonate and $10 \mathrm{mM}{ }^{13} \mathrm{C}$ pyruvate) and hyperpolarized $\left[1-{ }^{13} \mathrm{C}\right]$ pyruvate alone $(10 \mathrm{mM})$ within the same imaging exam. Injection of the copolarized solution was initiated approximately $10 \mathrm{~s}$ following dissolution, making the total time between dissolution and initiation of ${ }^{13} \mathrm{C}$ spectroscopic imaging $25 \mathrm{~s}$. For the hyperpolarized MR spectroscopic imaging studies, a double spin-echo pulse sequence with a small, variable flip-angle excitation pulse, adiabatic refocusing pulses, and a flyback echo-planar readout trajectory was used to acquire in-vivo $3 \mathrm{D}{ }^{13} \mathrm{C}$ MRSI(20). These used a half-echo FID acquisition, $8 \times 8$ matrix size, TR $=230 \mathrm{~ms}$, TE $=5 \mathrm{~ms}, 10 \mathrm{~mm}$ slice, $10 \times 10$ $\mathrm{mm}$ in-plane resolution for 1.0cc voxels, and a spectral window of $5000 \mathrm{~Hz}$ with 1024 points (TRAMP). The k-space data was acquired concentrically, with a progressive RF flip angle scheme to utilize all available magnetization. This resulted in a total acquisition time of 15 secs. A tube with $8 \mathrm{M}^{13} \mathrm{C}$ urea inserted alongside the mouse was used for RF pulse calibration. This data was processed using $5 \mathrm{~Hz}$ exponential apodization and Fourier transformed using inhouse software, as previously reported (6). For comparison studies in the TRAMP model, voxels were designated predominantly tumor versus benign, and $\mathrm{pH}$ and lactate to pyruvate ratios were determined using the relative peak heights of magnitude spectra. Significance was determined using a two-tailed Student t-test with $\mathrm{p}<0.05$ considered statistically significant. 


\section{Results}

\section{Co-polarization of ${ }^{13} \mathrm{C}$-Sodium Bicarbonate with [1-13 $\mathrm{C}$ ] Pyruvic Acid and $\mathrm{T}_{1}$ measurements}

A preparation method for ${ }^{13} \mathrm{C}$ sodium bicarbonate in glycerol was developed, allowing for reasonable ${ }^{13} \mathrm{C}$ sodium bicarbonate concentrations in the preparation $[1.8 \mathrm{M} \approx$ half that achieved previously for cesium bicarbonate (9)] and a high solution state polarization (12.7 \pm $1.9 \%$ ). The final concentration of sodium bicarbonate is currently limited by the lower solubility of sodium bicarbonate relative to cesium bicarbonate in water and the maximum volume of the preparation that can be polarized in the Hypersense DNP polarizer. Multicompound polarization of ${ }^{13} \mathrm{C}$-sodium bicarbonate $(1.8 \mathrm{M})$ in glycerol and neat $\left[1-{ }^{13} \mathrm{C}\right]$ pyruvic acid $\left(14.2 \mathrm{M}\right.$ ) was performed by freezing the ${ }^{13} \mathrm{C}$ preparations separately within the same sample cup, prior to placement in the polarizer. For both $11.7 \mathrm{~T}(\mathrm{~N}=3)$ and $3 \mathrm{~T}$ experiments $(\mathrm{N}=3)$, polarization of samples containing both ${ }^{13} \mathrm{C}$ sodium bicarbonate and ${ }^{13} \mathrm{C}$ pyruvate resulted in a build-up time constant of approximately $3500 \mathrm{~s}$, with greater than $95 \%$ polarization of the sample achieved at 3.5 hours. This polarization build-up time is longer than the polarization build-up time for ${ }^{13} \mathrm{C}$ pyruvate alone (build-up time constant $\approx 900 \mathrm{~s}$ ) but is comparable to the polarization build-up time of ${ }^{13} \mathrm{C}$ sodium bicarbonate alone. Following dissolution using EDTA/ $\mathrm{H}_{2} \mathrm{O}$, the concentrations of ${ }^{13} \mathrm{C}$ bicarbonate and $\left[1-{ }^{13} \mathrm{C}\right]$ pyruvate were $28.4 \mathrm{mM}$ and $5.2 \mathrm{mM}$, respectively, with an average $\mathrm{pH}$ of 7.8. The average solution state polarization was $15.7 \pm 1.2 \%$ for bicarbonate and $17.6 \pm 0.9 \%$ for pyruvate, which was not significantly different from the $\%$ polarization obtained for each compound alone (Table 1 ). Representative data are shown in Figure 1, which demonstrate large signal enhancements, and mono-exponential decay for $\left[1-{ }^{13} \mathrm{C}\right]$ pyruvate $(171 \mathrm{ppm}),\left[1-{ }^{13} \mathrm{C}\right]$ pyruvate hydrate $(179 \mathrm{ppm})$, $\left[1-{ }^{13} \mathrm{C}\right]$ lactate $(182 \mathrm{ppm}),{ }^{13} \mathrm{C}$ bicarbonate $(161 \mathrm{ppm})$ and ${ }^{13} \mathrm{C}$ carbon dioxide $(125 \mathrm{ppm})$, with no significant impurities noted in the hyperpolarized dynamic spectrum. The carbon dioxide resonance was $\approx 22$ fold smaller than the bicarbonate resonance. Calculated mean $\mathrm{T}_{1}$ 's at $11.7 \mathrm{~T}$ were $46.7 \pm 0.6 \mathrm{~s}$ for bicarbonate, and $47.7 \pm 1.1 \mathrm{~s}$ for pyruvate. At $3 \mathrm{~T}$ the mean $\mathrm{T}_{1}$ values were significantly longer for pyruvate $67.3 \pm 2.5 \mathrm{~s}$ than at $11.7 \mathrm{~T}$. The bicarbonate $\mathrm{T}_{1}$ was also longer $(49.7 \pm 2.9 \mathrm{~s})$ at $3 \mathrm{~T}$, but this difference was not significant. The measured $\mathrm{T}_{1}$ of carbon dioxide at $11.7 \mathrm{~T}(44.7 \pm 0.6 \mathrm{sec})$ was not significantly less than that of sodium bicarbonate.

\section{Murine Co-polarization Studies}

Co-polarized ${ }^{13} \mathrm{C}$ bicarbonate and $\left[1-{ }^{13} \mathrm{C}\right]$ pyruvate were injected into 1 normal and 4 tumorbearing TRAMP mice in order to determine whether images of pyruvate metabolism and $\mathrm{pH}$ could be simultaneously obtained and that the presence of the ${ }^{13} \mathrm{C}$ bicarbonate did not affect pyruvate metabolism. For animal studies, a larger sample containing both ${ }^{13} \mathrm{Cbicarbonate}$ and $\left[1-{ }^{13} \mathrm{C}\right]$ pyruvate was used, corresponding to injected concentrations of $55 \mathrm{mM}$ and $10 \mathrm{mM}$, respectively. As shown in Figures 2 and 3, well resolved hyperpolarized ${ }^{13} \mathrm{C}$ resonances for the labelled carbonyls of $\left[1-{ }^{13} \mathrm{C}\right]$ pyruvate, $\left[1-{ }^{13} \mathrm{C}\right]$ pyruvate hydrate, $\left[1-{ }^{13} \mathrm{C}\right]$ lactate, ${ }^{13} \mathrm{C}$ bicarbonate and ${ }^{13} \mathrm{C}$ carbon dioxide could be observed in both normal mice (Figure 2) and in tumor containing TRAMP mice (Figure 3). The chemical shifts of these compounds were not different from those observed in solution studies. Despite the significantly higher concentration of ${ }^{13} \mathrm{C}$ bicarbonate injected, and in contrast to what was observed in solution (Figure 1), the observed in vivo bicarbonate peak was lower than the pyruvate peak. The ${ }^{13} \mathrm{C}$ carbon dioxide peak observed was on average 22.4 fold lower than the ${ }^{13} \mathrm{C}$ bicarbonate peak.

As previously reported, integration of ${ }^{13} \mathrm{C}$ bicarbonate and ${ }^{13} \mathrm{C} \mathrm{CO}_{2}$ peaks, and application of the Henderson-Hasselbalch equation allowed calculation of $\mathrm{pH}$ on a voxel by voxel basis and the creation of a pH images (9), as well as the corresponding hyperpolarized lactate images. A representative data set acquired for a normal (wild-type) mouse is shown in Figure 2, demonstrating low levels of hyperpolarized lactate $(\mathrm{Lac} / \mathrm{Pyr}=0.20$ to 0.52$)$ and $\mathrm{pH}$ values in the normal physiologic range (7.28 to 7.40). Regions of highest hyperpolarized lactate in the 
normal mouse were in the kidneys due to excretion of lactate, with most of the tissues in the normal mouse abdomen demonstrating Lac/Pyr ratios in the 0.2 to 0.3 range. Initial studies in TRAMP animals demonstrated higher levels of hyperpolarized lactate and more acidic $\mathrm{pH}$ values within tumor. A representative study is depicted in Figure 3, showing higher levels of lactate ( $\mathrm{Lac} / \mathrm{Pyr}=0.43$ to 0.58$)$ and more acidic $\mathrm{pH}(6.6$ to 7.0$)$ in the region of the prostate tumor as compared to surrounding benign abdominal tissues. The ability to distinguish tumor from surrounding benign tissue was addressed by comparing voxels containing tumor $(\mathrm{N}=5)$ to those containing benign tissue $(\mathrm{N}=5)$. The average $\mathrm{pH}$ for the tumoral voxels $(6.80 \pm 0.15)$ was lower than that observed for those containing benign tissue $(7.02 \pm 0.18)$, although the results were not statistically significant $(\mathrm{P}=0.11)$. The average Lac/Pyr ratio observed for tumoral voxels $(0.53 \pm 0.19)$ was slightly higher than the ratio seen in benign tissues $(0.44 \pm$ $0.08)$, although not significantly $(\mathrm{P}=0.60)$. Evaluation was limited by the difficulty in choosing voxels that were predominantly benign versus predominantly malignant, given the coarse spatial resolution of the studies. An additional set of experiments was performed in order to address the impact of ${ }^{13} \mathrm{C}$ bicarbonate co-administration on $\left[1-{ }^{13} \mathrm{C}\right]$ pyruvic acid metabolism in vivo. Pyruvate metabolism was not significantly different $(\mathrm{P}=0.4)$ in TRAMP mice $(\mathrm{N}=4)$ that were injected with hyperpolarized $\left[1-{ }^{13} \mathrm{C}\right]$ pyruvate alone (mean tumor lactate to pyruvate ratio $(\mathrm{Lac} / \mathrm{Pyr})=0.47 \pm 0.18)$ and in combination with hyprpolarized ${ }^{13} \mathrm{C}$ bicarbonate (mean tumor $\mathrm{Lac} / \mathrm{Pyr}=0.41 \pm 0.18$ ) within the same study.

\section{Multi-compound polarization}

In order to demonstrate that more than two compounds could be polarized in the same sample without significant loss of $\mathrm{T}_{1}$ or enhancement, four substrates of metabolic and physiologic interest were polarized: $\left[1-{ }^{13} \mathrm{C}\right]$ pyruvic acid, ${ }^{13} \mathrm{C}$ sodium bicarbonate, $\left[1,1-{ }^{13} \mathrm{C}\right]$ fumaric acid, and $\left[1-{ }^{13} \mathrm{C}\right]$ urea. Again, these compounds were frozen separately in a Hypersense polarizer sample cup and polarized at a microwave frequency of $94.080 \mathrm{GHz}$. Since not every compound could be polarized at its ideal frequency, a compromise value was chosen to provide the best simultaneous polarization of the mixture. The multi-polarization had a build-up time constant of approximately $3500 \mathrm{~s}$, with greater than $95 \%$ polarization of the sample achieved at 3.5 hours identical to the co-polarization, indicating the polarization time was dominated by the slower polarization of ${ }^{13} \mathrm{C}$ sodium bicarbonate. On dissolution using EDTA/ $\mathrm{H}_{2} \mathrm{O}$, the concentrations of ${ }^{13} \mathrm{C}$ bicarbonate, $\left[1-{ }^{13} \mathrm{C}\right]$ pyruvate, $\left[1,1-{ }^{13} \mathrm{C}\right]$ fumaric acid, and $\left[1-{ }^{13} \mathrm{C}\right]$ urea were $10.8 \mathrm{mM}$, $2.8 \mathrm{mM}, 2.5 \mathrm{mM}$ and $7.8 \mathrm{mM}$ respectively, with a measured $\mathrm{pH}$ of 7.8-7.9. A representative resulting hyperpolarized spectrum $(\mathrm{t}=60 \mathrm{~s})$ is presented in Figure $4(\mathrm{a})$, with calculated $\mathrm{T}_{1}$ 's, and enhancements presented in Table 1. Figure 4 demonstrates well-resolved resonances for all of the ${ }^{13} \mathrm{C}$ labelled carbonyls; $\left[1-{ }^{13} \mathrm{C}\right]$ pyruvate $(171 \mathrm{ppm}),\left[1-{ }^{13} \mathrm{C}\right]$ pyruvate hydrate $(179$ ppm), ${ }^{13} \mathrm{C}$ bicarbonate (161 ppm) and ${ }^{13} \mathrm{C}$ carbon dioxide $(125 \mathrm{ppm})$, urea (164 ppm) and fumurate $(175 \mathrm{ppm})$ with one unknown small impurity at $160 \mathrm{ppm}$. In a second set of experiments, the compounds were polarized separately under identical conditions, and dissolved in a high buffering-capacity buffer to ensure a similar $\mathrm{pH}$ (7.8) to that observed for the multi-metabolite case. In all cases the calculated $\mathrm{T}_{1}$ 's and enhancements were similar, demonstrating that multi-compound polarization can be achieved with minimal if any loss of SNR (Table 1). For in vivo applications, the polarization protocol was modified slightly in order to allow higher concentrations of the hyperpolarized ${ }^{13} \mathrm{C}$ agents, and minimize loss of solution-state polarization following dissolution. Representative data are shown in Figure 4(b) demonstrating resolution of all four metabolites in vivo at high SNR, albeit with relatively coarse spatial resolution $\left(1 \mathrm{~cm}^{3}\right)$.

\section{Discussion}

Multi-metabolite polarization is intended to circumvent one of the main drawbacks of DNP, namely its long polarization times, by polarizing several precursors at the same time, and then 
developing a biological scenario whereby the inevitably very complex metabolic data in vivo can be analyzed. In this study, a method for direct polarization of ${ }^{13} \mathrm{C}$ sodium bicarbonate suitable for use in patients was developed, and the co-polarization of ${ }^{13} \mathrm{C}$ sodium bicarbonate and $\left[1-{ }^{13} \mathrm{C}\right]$ pyruvate in a single intravenous bolus was achieved for the first time. The polarization build-up time was longer than the polarization build-up time for $\left[1-{ }^{13} \mathrm{C}\right]$ pyruvate alone (build-up time constant $\approx 900$ s) due to the longer polarization build-up time of ${ }^{13} \mathrm{C}$ sodium bicarbonate. However, the use of gadolinium contrast agent in the preparation can significantly increase the polarization of the compound ( $19.3 \pm 1.4 \%$ in initial studies, $\mathrm{N}=3)$, which can either increase the overall signal or decrease the build-up time to achieve the same signal. The ${ }^{13} \mathrm{C}$ sodium bicarbonate preparation provided hyperpolarized bicarbonate concentrations that were approximately half $(55 \mathrm{mM})$ that previously reported for cesium bicarbonate $(100 \mathrm{mM})$, and similar solution state polarizations $(\approx 16 \%)$ without the need for chromatography following dissolution to remove the cesium (9). Consistent with chemical shift anisotropy dominating the $\mathrm{T}_{1}$ relaxation of carbonyls, the $\mathrm{T}_{1}$ 's of ${ }^{13} \mathrm{C}$ bicarbonate and $\left[1-{ }^{13} \mathrm{C}\right]$ pyruvate were even longer at $3 \mathrm{~T}(49.7 \mathrm{~s}$ and $67.3 \mathrm{~s}$, respectively) as compared to $11.7 \mathrm{~T}$ $(21,22)$ As predicted by the Henderson-Hasselbalch equation $\left(\mathrm{pH}=\mathrm{pKa}+\log _{10}\left(\left[\mathrm{HCO}_{3}{ }^{-}\right] /\right.\right.$ $\left[\mathrm{CO}_{2}\right], \mathrm{pKa}=6.17$ ) (9) and the known $\mathrm{pH}$ and temperature of the solution, the carbon dioxide resonance was $\approx 22$ fold less than the bicarbonate resonance. However, the co-polarization resulted in sufficiently high solution state polarizations and spin-lattice relaxation times of bicarbonate, carbon dioxide and pyruvate to acquire simultaneous in vivo images of interstitial $\mathrm{pH}$ and pyruvate metabolism in normal and tumor-bearing mice.

Despite the significantly higher concentration of ${ }^{13} \mathrm{C}$ bicarbonate than $\left[1-{ }^{13} \mathrm{C}\right]$ pyruvate injected in animal in vivo studies, and in contrast to what was observed in solution, the observed in vivo bicarbonate peak was much lower than the pyruvate peak. This reduction in hyperpolarized signal may be the result of ${ }^{13} \mathrm{C}$ carbon dioxide loss during the dissolution process, the much shorter in vivo $\mathrm{T}_{1}$ of ${ }^{13} \mathrm{C}$ bicarbonate and carbon dioxide (9), as well as loss of ${ }^{13} \mathrm{C}$ carbon dioxide in the lungs with ventilation. The in vivo $\mathrm{T}_{1}$ of ${ }^{13} \mathrm{C}$ bicarbonate and carbon dioxide has been previously reported to be $\approx 10$ seconds, much shorter than the $\approx 50$ seconds reported in the solution studies described herein. Most important for in vivo measurements of $\mathrm{pH}$ is the fact that the $\mathrm{T}_{1}$ of ${ }^{13} \mathrm{C}$ bicarbonate and carbon dioxide are similar as reported in the solution state in this paper and in vivo previously (9). The equivalence of the $\mathrm{T}_{1}$ 's is most likely due to the rapid inter-conversion of ${ }^{13} \mathrm{C}$ bicarbonate and carbon dioxide, since even in the absence of carbonic anhydrase the exchange is rapid $\left(\approx 0.1 \mathrm{~s}^{-1}\right)$ and accelerated by the enzyme (9).

Moreover, sufficient $\mathrm{S} / \mathrm{N}$ data were obtained for magnetic resonance spectroscopic imaging studies with a $1 \mathrm{~cm}^{3}$ spatial resolution. This relatively coarse spatial resolution was mandated by the roughly 20 -fold difference in ${ }^{13} \mathrm{C} \mathrm{CO}_{2}$ peak signal-to-noise relative to the ${ }^{13} \mathrm{C}$

bicarbonate peak for $\mathrm{pH}$ 's in the physiologic range. However, this limitation in sensitivity can be overcome by increasing the amount of hyperpolarized ${ }^{13} \mathrm{C}$ bicarbonate infused. In the current study, the bicarbonate preparation in glycerol was $1.8 \mathrm{M}$, limiting the concentration of injected bicarbonate to $55 \mathrm{mM}$ using existing methods on the Oxford Hypersense polarizer. When this method is applied to patient studies, the ${ }^{13} \mathrm{C}$ bicarbonate concentration will not be a problem since clinical DNP polarizers will have the ability to polarize and dissolve larger amounts of ${ }^{13} \mathrm{C}$ bicarbonate than the current Hypersense DNP polarizer. Bicarbonate is often infused into patients at high concentrations on the order of $150 \mathrm{mM}$.

Similar to what has been previously reported for the injection of hyperpolarized $\left[1-{ }^{13} \mathrm{C}\right]$ pyruvate alone in the normal and TRAMP mouse, higher levels of hyperpolarized $\left[1-{ }^{13} \mathrm{C}\right]$ lactate were observed in the TRAMP tumor compared to benign tissues in the abdomen of the mouse after injection of co-polarized ${ }^{13} \mathrm{C}$ bicarbonate and $\left[1-{ }^{13} \mathrm{C}\right]$ pyruvate $(6)$. However, given the limited sample size and relatively coarse spacial resolution achieved, more studies are clearly needed to validate changes in $\mathrm{pH}$ and $\left[1-{ }^{13} \mathrm{C}\right]$ pyruvate metabolism in the TRAMP model, interrogated via this method. Importantly, the presence of bicarbonate did not change 
the observed pyruvate metabolism with the same tumor hyperpolarized lactate/pyruvate ratios being obtained when pyruvate was administered alone or in combination with bicarbonate. Rapid equilibration of injected hyperpolarized ${ }^{13} \mathrm{C}$ sodium bicarbonate with ${ }^{13} \mathrm{C} \mathrm{CO}_{2}$ after injection in mice also allowed the calculation of $\mathrm{pH}$ on a voxel by voxel basis as previously described in a study of hyperpolarized ${ }^{13} \mathrm{C}$ cesium bicarbonate in a murine lymphoma model (9). Our initial TRAMP studies demonstrated a tumoral $\mathrm{pH}$ similar to what has been previously reported for the $\mathrm{pH}$ of the EL4 tumor $(\mathrm{pH}=6.71 \pm 0.14)(9)$. These initial data suggested that the more acidic $\mathrm{pH}$ observed in cancerous tissue correlated with increased pyruvate to lactate conversion, supporting the hypothesis that the cellular evolution associated with carcinogenesis selects for lactate production resulting in microenvironmental acidosis. It has been proposed that this microenvironmental acidosis enables the malignant cells to breakdown and invade neighbouring tissue $(23,24)$. However, additional studies need to be performed in order to verify the correlation between hyperpolarized lactate production and decreased interstitial $\mathrm{pH}$, and determine whether decreased tumor $\mathrm{pH}$ correlates with increasing pathologic grade as previously shown for hyperpolarized lactate production (6).

The co-polarization technique was extended to polarize four ${ }^{13} \mathrm{C}$ labelled substrates, namely $\left[1-{ }^{13} \mathrm{C}\right]$ pyruvic acid, ${ }^{13} \mathrm{C}$ sodium bicarbonate, $\left[1,4-{ }^{13} \mathrm{C}\right]$ fumaric acid, and ${ }^{13} \mathrm{C}$ urea, in vitro demonstrating the potential of obtaining information on $\mathrm{pH}$, metabolism, necrosis and perfusion, with high levels of solution state polarization (10-20\%) and spin-lattice relaxation values (30-50s) similar to those obtained with polarization of the individual hyperpolarized probes. In addition, initial studies demonstrated that these four ${ }^{13} \mathrm{C}$ probes could be simultaneously detected in vivo, at high SNR. Several challenges were encountered with respect to polarization and dissolution of these four probes. First, as discussed previously the Oxford Hypersense polarizer is limited in its ability to dissolve large volumes of ${ }^{13} \mathrm{C}$ sample preparations. Second, differences in ideal microwave irradiation frequencies for the four compounds resulted in several ${ }^{13} \mathrm{C}$ compounds being polarized off-resonance, limiting their solid-state polarization. Finally, fast chemical interactions (specifically acid-base) between polarized ${ }^{13} \mathrm{C}$ species in solution is likely limiting their solution-state polarization, and may in some cases affect $\mathrm{T}_{1}$. For example, when polarizing organic acids (such as fumaric acid and pyruvic acid) with sodium bicarbonate, a significant titration occurs during dissolution, with rapid generation of carbonic acid (and therefore $\mathrm{CO}_{2}$ ), which reduces the hyperpolarized ${ }^{13} \mathrm{C}$ bicarbonate signal obtained both in vitro and in vivo. For the multimetabolite studies, the detection of ${ }^{13} \mathrm{C} \mathrm{CO}_{2}$ was again limiting, and reliable $\mathrm{pH}$ values were not obtained. Future efforts will focus on augmenting the $\mathrm{CO}_{2}$ resonance for high-resolution multi-metabolite studies employing these four compounds. ${ }^{13} \mathrm{C}$ urea has already been employed as an intravascular angiographic agent, and could be used in the described agent combination to assess tissue perfusion $(1,7)$. $\left[1,4-{ }^{13} \mathrm{C}\right]$ fumarate represents a point of entry into the citric acid cycle and has recently been shown to be a marker of treatment response through increased production of hyperpolarized $\left[1,4-{ }^{13} \mathrm{C}\right]$ malate due to increased cellular necrosis after therapy (25). The labelled carbons of $\left[1,4-{ }^{13} \mathrm{C}\right]$ fumarate are magnetically equivalent $(175 \mathrm{ppm})$, while the $\left[1,4-{ }^{13} \mathrm{C}\right]$ malate carbons are not equivalent $\left(\left[1-{ }^{13} \mathrm{C}\right] 181.8 \mathrm{ppm},\left[4-{ }^{13} \mathrm{C}\right] 180.6 \mathrm{ppm}\right)$. In a multipolarization experiment, the $\left[1-{ }^{13} \mathrm{C}\right]$ resonance of malate can therefore overlap the $\left[1-{ }^{13} \mathrm{C}\right]$ resonance of lactate $(182 \mathrm{ppm})$. Since the magnitude of the $\left[1-{ }^{13} \mathrm{C}\right]$ and $\left[4-{ }^{13} \mathrm{C}\right]$ resonances of malate are equal and the $\left[4-{ }^{13} \mathrm{C}\right]$ resonances does not overlap other resonances, it can be used to separate malate from lactate. For in vivo applications that have limited spectral resolution, deconvolution may be necessary to discern relative intensities of lactate and malate.

Simultaneous evaluation of enzymatic pathways and other physiologic properties is not easily achieved using other imaging methods including PET, optical imaging, or other targeted MR methods. As additional new ${ }^{13} \mathrm{C}$ agents are developed, multi-compound polarization will be a powerful method of probing multiple metabolic pathways and other physiologic properties simultaneously, in a single MR scan lasting only seconds. 


\section{Acknowledgments}

We would like to acknowledge funding from the National Institutes of Health (R21 EB005363, R01 EB007588); NIBIB T32 Training Grant 1 T32 ED001631 as well as support from GE Healthcare.

\section{References}

1. Ardenkjaer-Larsen JH, et al. Increase in signal-to-noise ratio of > 10,000 times in liquid-state NMR. Proc Natl Acad Sci U S A 2003;100(18):10158-10163. [PubMed: 12930897]

2. Golman K, Ardenkjaer-Larsen JH, Petersson JS, Mansson S, Leunbach I. Molecular imaging with endogenous substances. Proc. Natl. Acad. Sci. U.S.A 2003;100(18):10435-10439. [PubMed: 12930896]

3. Golman K, Zandt RI, Lerche M, Pehrson R, Ardenkjaer-Larsen JH. Metabolic imaging by hyperpolarized $13 \mathrm{C}$ magnetic resonance imaging for in vivo tumor diagnosis. Cancer Res 2006;66 (22):10855-10860. [PubMed: 17108122]

4. Kohler SJ, et al. In vivo 13 carbon metabolic imaging at 3T with hyperpolarized 13C-1-pyruvate. Magn Reson Med 2007;58(1):65-69. [PubMed: 17659629]

5. Merritt ME, et al. Hyperpolarized 13C allows a direct measure of flux through a single enzymecatalyzed step by NMR. (Translated from eng). Proc Natl Acad Sci U S A 2007;104(50):19773-19777. (in eng). [PubMed: 18056642]

6. Albers MJ, et al. Hyperpolarized 13C lactate, pyruvate, and alanine: noninvasive biomarkers for prostate cancer detection and grading. (Translated from eng). Cancer Res 2008;68(20):8607-8615. (in eng). [PubMed: 18922937]

7. Golman K, et al. Molecular imaging using hyperpolarized 13C. (Translated from eng). Br J Radiol 2003;76(Spec No 2):S118-S127. (in eng). [PubMed: 15572334]

8. Warburg O. [Origin of cancer cells]. (Translated from ger). Oncologia 1956;9(2):75-83. (in ger). [PubMed: 13335077]

9. Gallagher FA, et al. Magnetic resonance imaging of $\mathrm{pH}$ in vivo using hyperpolarized 13C-labelled bicarbonate. (Translated from eng). Nature 2008;453(7197):940-943. (in eng). [PubMed: 18509335]

10. Gallagher FA, Kettunen MI, Day SE, Lerche M, Brindle KM. 13C MR spectroscopy measurements of glutaminase activity in human hepatocellular carcinoma cells using hyperpolarized 13C-labeled glutamine. (Translated from eng). Magn Reson Med 2008;60(2):253-257. (in eng). [PubMed: 18666104]

11. Schroeder MA, et al. Real-time assessment of Krebs cycle metabolism using hyperpolarized 13C magnetic resonance spectroscopy. (Translated from eng). FASEB J. 2009 (in eng).

12. Chen AP, et al. Feasibility of using hyperpolarized [1-13C]lactate as a substrate for in vivo metabolic 13C MRSI studies. (Translated from eng). Magn Reson Imaging 2008;26(6):721-726. (in eng). [PubMed: 18479878]

13. Keshari KR, et al. Hyperpolarized [2-13C]-fructose: a hemiketal DNP substrate for in vivo metabolic imaging. (Translated from eng). J Am Chem Soc 2009;131(48):17591-17596. (in eng). [PubMed: 19860409]

14. Dillon WP, Nelson S. What is the role of MR spectroscopy in the evaluation and treatment of brain neoplasms? (Translated from eng). AJNR Am J Neuroradiol 1999;20(1):2-3. (in eng). [PubMed: 9974048]

15. Kurhanewicz J, Swanson MG, Nelson SJ, Vigneron DB. Combined magnetic resonance imaging and spectroscopic imaging approach to molecular imaging of prostate cancer. (Translated from eng). $\mathrm{J}$ Magn Reson Imaging 2002;16(4):451-463. (in eng). [PubMed: 12353259]

16. Hohn-Berlage M, Okada Y, Kloiber O, Hossmann KA. Imaging of brain tissue $\mathrm{pH}$ and metabolites. A new approach for the validation of volume-selective NMR spectroscopy. (Translated from eng). NMR Biomed 1989;2(5-6):240-245. (in eng). [PubMed: 2701807]

17. Syrota A, et al. Tomographic mapping of brain intracellular $\mathrm{pH}$ and extracellular water space in stroke patients. (Translated from eng). J Cereb Blood Flow Metab 1985;5(3):358-368. (in eng). [PubMed: 3875620] 
18. Schindler M, Grabski S, Hoff E, Simon SM. Defective $\mathrm{pH}$ regulation of acidic compartments in human breast cancer cells (MCF-7) is normalized in adriamycin-resistant cells (MCF-7adr). (Translated from eng). Biochemistry 1996;35(9):2811-2817. (in eng). [PubMed: 8608115]

19. Ciriolo MR, et al. Loss of GSH, oxidative stress, and decrease of intracellular $\mathrm{pH}$ as sequential steps in viral infection. (Translated from eng). J Biol Chem 1997;272(5):2700-2708. (in eng). [PubMed: 9006907]

20. Cunningham $\mathrm{CH}$, et al. Double spin-echo sequence for rapid spectroscopic imaging of hyperpolarized 13C. (Translated from eng). J Magn Reson 2007;187(2):357-362. (in eng). [PubMed: 17562376]

21. Anet FAL, O'Leary DJ. The Shielding Tensor. Concepts in Magnetic Resonance 1992;4:35-52.

22. Blicharski JS. Nuclear Magnetic Relaxation by Anisotropy of the Chemical Shift. Z. Naturforsch A 1972;(27):1456-1458.

23. Gatenby RA, Gillies RJ. Why do cancers have high aerobic glycolysis? Nat Rev Cancer 2004;4(11): 891-899. [PubMed: 15516961]

24. Gatenby RA, Gawlinski ET, Gmitro AF, Kaylor B, Gillies RJ. Acid-Mediated Tumor Invasion: a Multidisciplinary Study. Cancer Res 2006;66(10):5216-5223. [PubMed: 16707446]

25. Gallagher FA, et al. Production of hyperpolarized [1,4-13C2]malate from [1,4-13C2]fumarate is a marker of cell necrosis and treatment response in tumors. (Translated from eng). Proc Natl Acad Sci U S A 2009;106(47):19801-19806. (in eng). [PubMed: 19903889] 


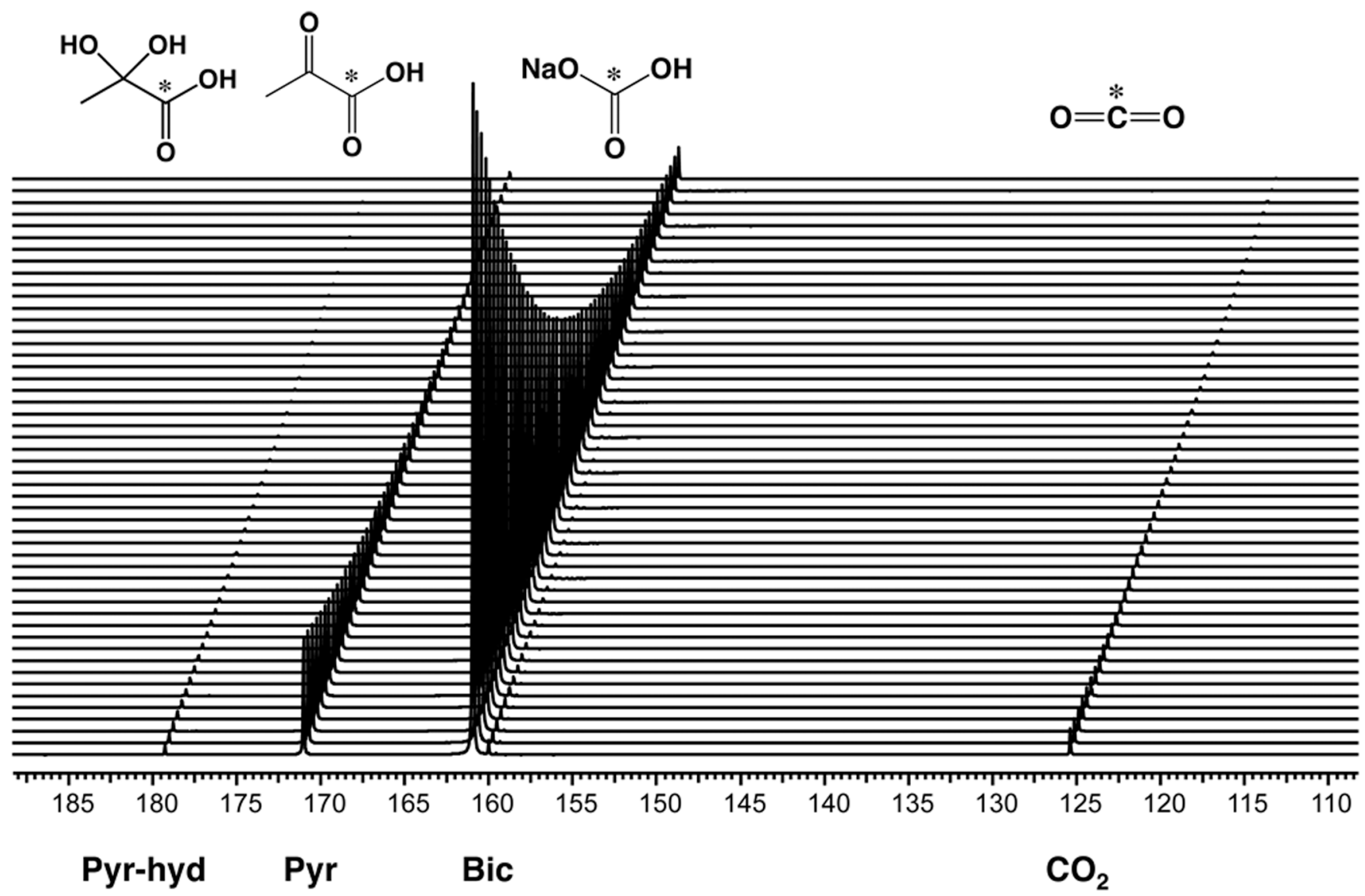

Figure 1.

Dynamic hyperpolarized spectrum for a co-polarized solution of $\left[1-{ }^{13} \mathrm{C}\right]$ pyruvate and ${ }^{13} \mathrm{C}$ sodium bicarbonate, with data collected at $11.7 \mathrm{~T}$. The final solution $\mathrm{pH}$ was 7.8-7.9. The monoexponential decay for bicarbonate and pyruvate peaks were used to calculate the $\mathrm{T}_{1}$ 's. 
a.

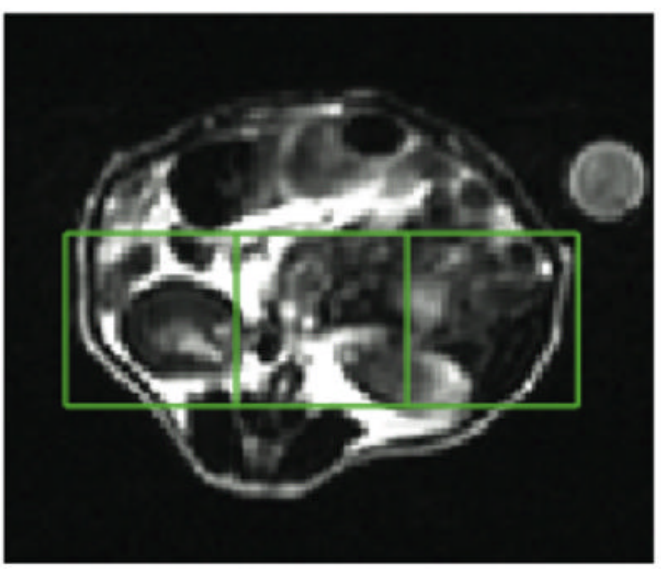

c.

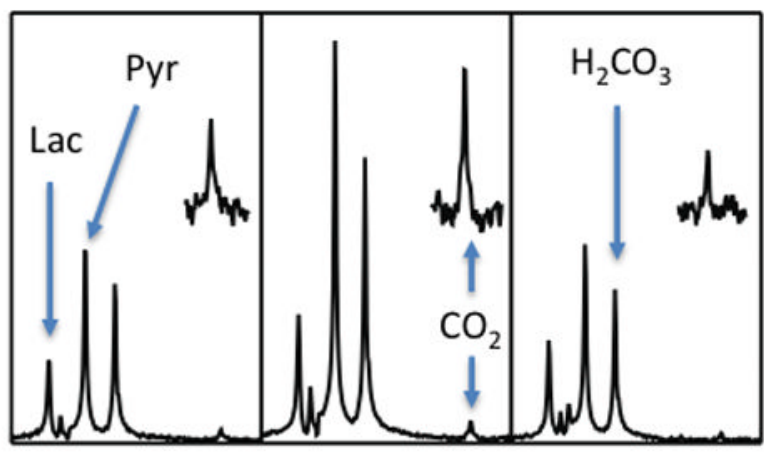

pH: 7.28

$\mathrm{pH}: 7.32$

$\mathrm{pH}: 7.40$

Lac/Pyr: 0.43 Lac/Pyr: 0.32 Lac/Pyr: 0.52

b.

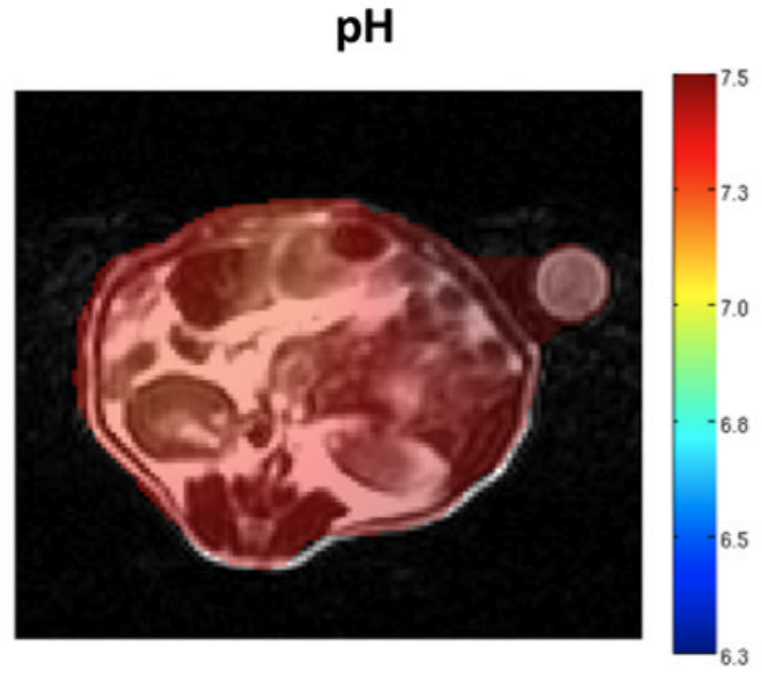

\section{Lactate/Pyruvate}

d.

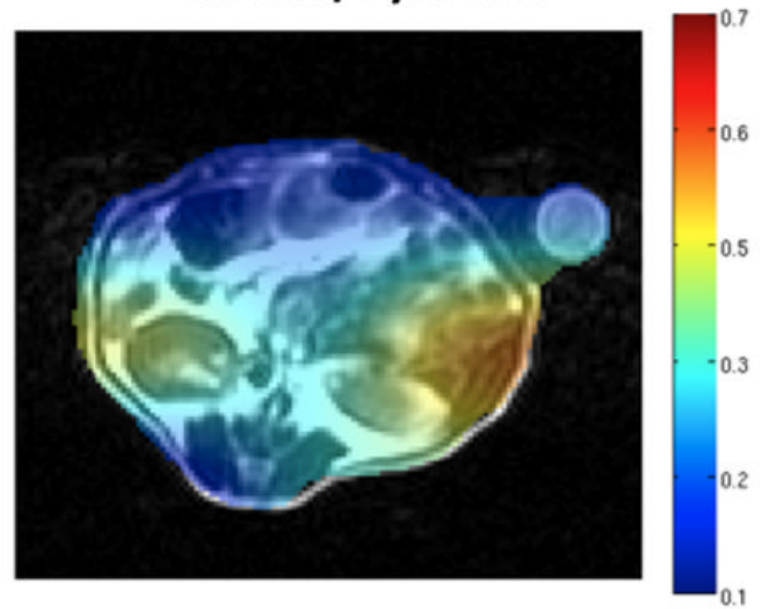

Figure 2.

In vivo data collected at $3 \mathrm{~T}$. $\mathrm{A}_{2}$ weighted anatomic image $(\mathrm{A}), \mathrm{pH}$ image of the same slice demonstrating the distribution of calculated $\mathrm{pH}(\mathrm{B})$, spectra for the corresponding voxels shown in the T2 weighted image (C) and the lactate/pyruvate ratio image (D) are shown for a wildtype mouse. Following dissolution, $300 \mu \mathrm{L}$ of a solution with $55 \mathrm{mM}$ pre-polarized ${ }^{13} \mathrm{C}$ bicarbonate and $10 \mathrm{mM}{ }^{13} \mathrm{C}$ pyruvate were injected intravenously. Data were acquired with a resolution of $1 \mathrm{~cm}^{3}$. The $\mathrm{pH}$ for individual voxels was calculated using the HendersonHasselbalch equation and $\mathrm{pK}_{\mathrm{a}}$ of 6.17 at $37^{\circ} \mathrm{C}$. The peak ratios of observed ${ }^{13} \mathrm{C}$ lactate to ${ }^{13} \mathrm{C}$ pyruvate are shown beneath the corresponding spectra. Regions of the $\mathrm{CO}_{2}$ resonance have been scaled up to demonstrate the signal-to-noise achieved in each voxel. 
a.

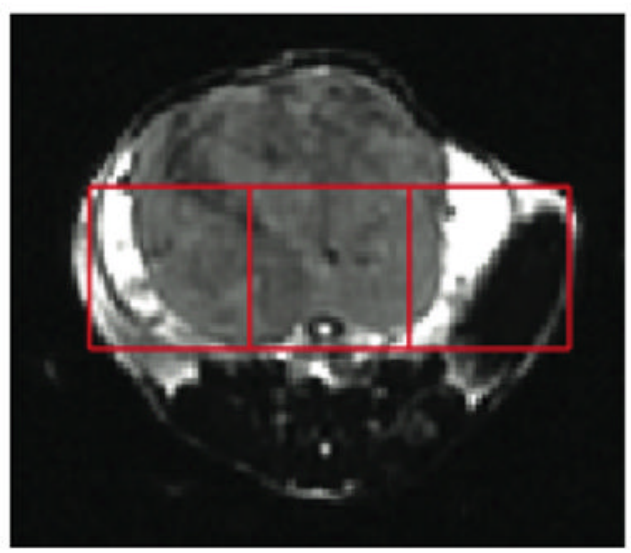

C.

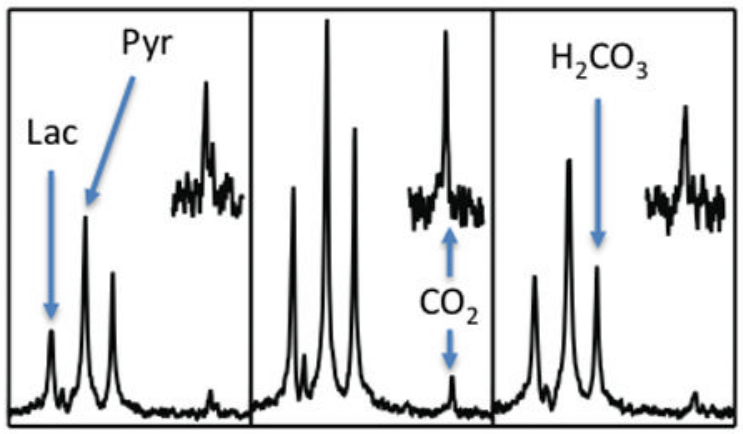

$\mathrm{pH}: 6.87$

$\mathrm{pH}: 7.00$

$\mathrm{pH}: 6.91$

Lac/Pyr: 0.43 Lac/Pyr: 0.58 Lac/Pyr: 0.55 b.

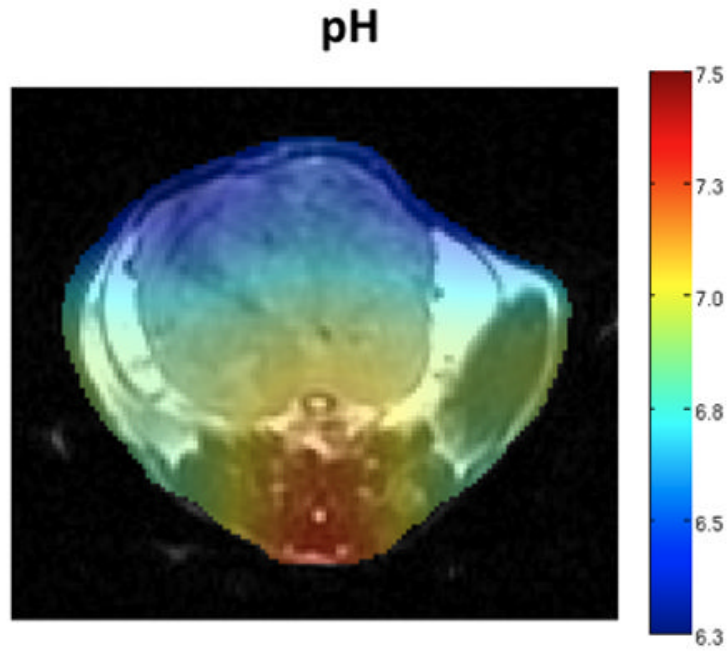

d.

\section{Lactate/Pyruvate}

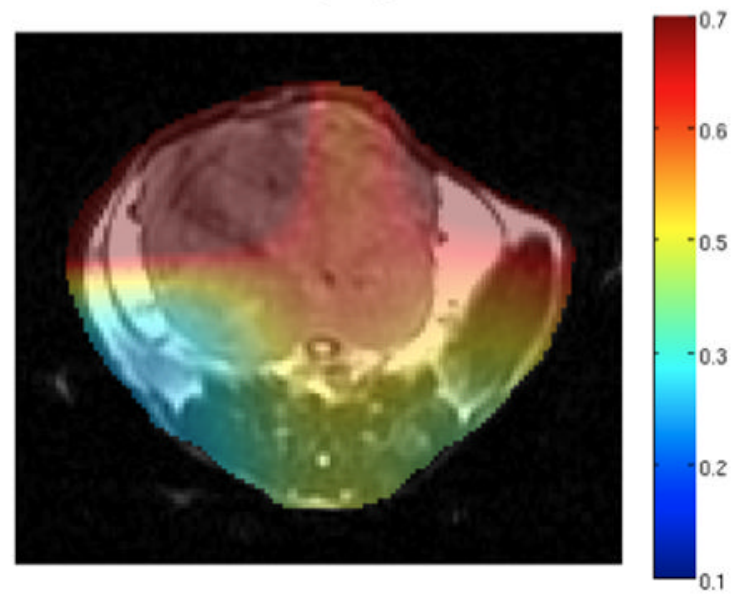

Figure 3.

In vivo data collected at $3 \mathrm{~T}$. $\mathrm{A} \mathrm{T}_{2}$ weighted anatomic image (A), $\mathrm{pH}$ image of the same slice demonstrating the distribution of $\mathrm{pH}$ calculated (B), spectra for the corresponding voxels shown in the T2 weighted image (C) and the Lactate/Pyruvate ratio image (D) are shown for a TRAMP tumor bearing mouse. The tumor is visible in the upper half of the slice. Following dissolution, $300 \mu \mathrm{L}$ of a solution $55 \mathrm{mM}$ in pre-polarized ${ }^{13} \mathrm{C}$ bicarbonate and $10 \mathrm{mM}$ in ${ }^{13} \mathrm{C}$ pyruvate were injected intravenously. Data was acquired with a resolution of $1 \mathrm{~cm}^{3}$. The $\mathrm{pH}$ for individual voxels was calculated using the Henderson-Hasselbalch equation and $\mathrm{pK}_{\mathrm{a}}$ of 6.17 at $37^{\circ} \mathrm{C}$. The peak ratios of observed ${ }^{13} \mathrm{C}$ lactate to ${ }^{13} \mathrm{C}$ pyruvate are also shown beneath the corresponding spectra. Regions of the $\mathrm{CO}_{2}$ resonance have been scaled up to demonstrate the signal-to-noise achieved in each voxel. 
a.

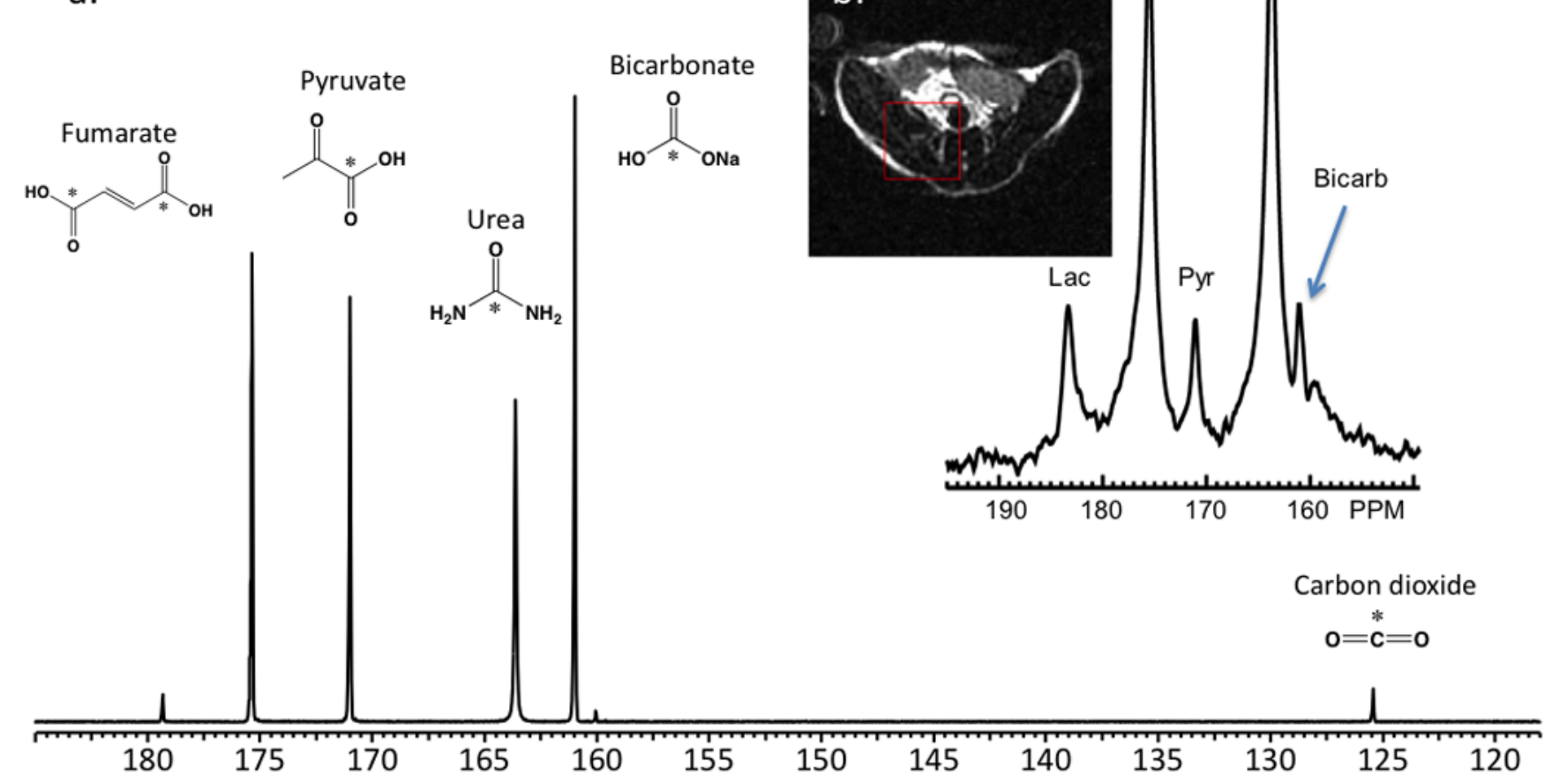

Figure 4.

(a) Multi-compound polarization of four ${ }^{13} \mathrm{C}$ biomolecules of interest: fumarate, pyruvate, urea, and bicarbonate in vitro. These data were obtained in a $10 \mathrm{~mm}$ NMR tube $60 \mathrm{~s}$ following dissolution at 11.7T. Levels of polarization achieved were similar to that obtained for the individual compounds, performed using an optimized microwave frequency. $\mathrm{T}_{1}$ 's in solution were similar to those obtained for the separate species. Standard deviations are reported $(\mathrm{N}=3)$. (b) Multi-compound polarization in vivo performed in a TRAMP mouse model at $3 \mathrm{~T}$. 


\section{TABLE 1}

Spin-lattice relaxation values, and \% polarization achieved for multi-compound polarization at 11.7T. $\mathrm{T}_{1}$ 's and signal enhancements were similar to those observed when the individual compounds were polarized separately and dissolved in an identical 100mM pH 7.8 phosphate buffer. Standard deviations are reported $(\mathrm{N}=3)$.

\begin{tabular}{ccccc}
\hline Compound & $\begin{array}{c}\mathbf{T}_{\mathbf{1}}(\mathbf{s}) \\
\text { multipol }\end{array}$ & $\begin{array}{c}\mathbf{T}_{\mathbf{1}}(\mathbf{s}) \\
\text { alone }\end{array}$ & $\begin{array}{c}\text { \% polarization } \\
\text { multipol }\end{array}$ & $\begin{array}{c}\text { \% polarization } \\
\text { alone }\end{array}$ \\
\hline${ }^{13} \mathrm{C}$ bicarbonate & $43.3 \pm 1.2$ & $48.7 \pm 0.6$ & $10.3 \pm 1.8$ & $12.7 \pm 1.9$ \\
{$\left[1-{ }^{13} \mathrm{C}\right]$ pyruvate } & $48.3 \pm 1.5$ & $48.3 \pm 0.6$ & $17.5 \pm 3.4$ & $17.4 \pm 1.5$ \\
{$\left[1,1-{ }^{13} \mathrm{C}\right]$ fumarate } & $29.0 \pm 1.0$ & $29.3 \pm 0.6$ & $15.6 \pm 1.9$ & $12.0 \pm 0.7$ \\
{$\left[1-{ }^{13} \mathrm{C}\right]$ urea } & $43.0 \pm 1.0$ & $44.0 \pm 0.3$ & $11.6 \pm 2.5$ & $12.4 \pm 0.4$ \\
\hline
\end{tabular}

